\title{
The Effect of Particle Dispersion due to Mixing Speed on Spent Coffee Ground Composites
}

\author{
Sumarji*, Fabrobi Ridha, Dedi Dwilaksana, Ahmad Syuhri, Raihaan \\ Department of Mechanical Engineering, University of Jember, \\ Jember, Indonesia
}

Correspondence: E-mail: sumarji.mesin@gmail.com

\begin{abstract}
A B S T R A C T
Composites using bio-materials with unique properties, such as spent coffee ground were developed for composite fillers. This study was conducted to produce samples under various mixing speed conditions. This study also determined effect of mixing speeds on particle homogeneity as well as composite dispersion in the final product. The composite dispersion was determined by an index based on a standard deviation of free-path spacing of filler particles using a digital microscope. Results showed that when using high-speed mixing, particle tends to agglomerate with particle clumps. We also obtained that faster mixing speed results more homogeneous mixture compared to slower speed. In short, slower speed can reach similar result in homogeneity levels, but it would require longer time for the mixing process.
\end{abstract}

\section{ARTICLE INFO}

Article History:

Submitted/Received 21 Des 2018

First revised 13 Apr 2019

Accepted 12 Jun 2019

First available online 14 Jun 2019

Publication date 01 Sep 2019

\section{Keywords:}

Digital microscopy,

Particle dispersion,

SCG composite,

Solid liquid mixing. 


\section{INTRODUCTION}

Composites have been widely applied and developed in wide range of uses due to their properties and flexibility during the manufacturing process (Bale et al., 2019). Composites also have been studied in various fields, including the use for material fillers (Mavhungu et al., 2017 ; Wu, 2015 ). One of the products that can be used as a composite is spent coffee grounds (SCG).

SCG particles are an alternative for materials that could be recycled and re-used for its availability. Approximately 314,400 tons of coffee are consumed by Indonesian and most of their wastes are disposed and unlikely to be re-used (Zarrinbakhsh et al., 2016). Development of these materials into a useful resource would be an advancement in the renewable material department.

Application of SCG has been welldocumented and reported for special purposes, such as odor removers (Woo et al., 2017), a water remediator (Chavan et al., 2016), or a colorant. SGC also could be used for fillers. Further, we can manufacture SGC based on how we utilize them. In this study, SGC was produced using hand lay-up since this method is one of the most basic methods for manufacturing composites (Mohanty et al., 2018). Hand lay-up has high adaptability (Elkington et al., 2015) and applying the right amount of variables is possible. Its flexibility in the manufacturing process would help it be less complex in the observation of filler particles (Mohanty et al., 2018). For understanding the effect of specific variables on the manufacturing process, we limited variables.

To be applied as filler, SGC particle distribution is a critical variable, influencing properties of the composite. A more homogenized distribution of the fillers would contribute in increasing mechanical properties, heat, and electrical distribution and therefore change the performance of the final composite (Oh et al., 1998; Prabu et al., 2006).

The variety from the dispersion of particles may be attributed to properties of matrix, particle sizes, particle volume (or weight fraction), and its processing steps that are required. This includes chemical and physical mechanisms that influence the particles' interface. With the multicomponent nature of the system, it is difficult to identify the particular process controlling the observed effects (Barabash et al., 2018). Therefore, mixing techniques which has a significant role in industrial process of particle composites would suit in an empirical study.

The mixing of matrix and particles from aggregates/agglomerates and continued through free dispersion would be that of fluid-solid material mix and would adhere to matrix fluid principles. This would be in hand by applying computational fluid dynamics as a main method in fundamental research for predicting local fluid dynamics. Due to the complexity of dispersion and the unsteadiness of fluid flow, however, simulations in that regard are less desired (Barabash et al., 2018).

Indicators for a successful solid-fluid mixture would be done in the complete suspension. This requires a minimum mixing impeller speed where an under-speed would result in an unsuspended mixture that would have no effect in observation (Kraume, 1992). With the increases in higher impeller speed, the mixing time would decrease but this puts the system in a need of extra energy spent for solid-liquid interface and less energy for mixing (Bujalski et al., 1999; Rao and Joshi, 1988). Impeller speed employed is determined with respect to the characteristics of matrix to obtain complete suspension. In this study, it would 
be established as a variable, as mixing speed would be a sensible standard of comparison.

The dispersions of materials would lead to characterize the microstructural and quantifying the homogeneity. This has been developed by several researches through microscopy analyses (Luo and Koo, 2007; Paciornik and D'almeida, 2009; Yakaboylu and Sabolsky, 2017). The quantitative measurement indexes in this case pertains to a study of composites, considering the pattern of microstructure. Yakaboylu's method quantifies the dispersion and models his research mainly on binary composites while limiting factors that reduces accuracy and therefore a good option to employ. By developing the indexes, a certain trend in determining good dispersion standard of particles could be developed and quantified.

\section{MATERIALS AND METHODS}

The method of manufacturing samples was described in the following. Waste spent coffee grounds were collected from local coffee shops and its humidity decreased to under $5 \%$ by oven drying. The grounds are then processed using mortar and pestle for decreasing clumps. Resultant was filtered with sieves of mesh 80 as this particle size ensues good mechanical properties (Fu et al., 2008). Density measurement of SCG is 514 $\mathrm{kg} / \mathrm{m}^{3}$ using ASTM D6683-03. The resin type utilized was ETERSET 2504 APT with a viscosity (ranging from 300 to $600 \mathrm{cps}$ ) and density of $1120 \mathrm{~kg} / \mathrm{m}^{3}$ (de Melo et al., 2014). The fractions of solids and resin in this case is 40 and $60 \mathrm{wt} \%$, respectively, and should be considered when determining the mixing speed. Kraume developed mixing times of over $100 \mathrm{~s}$ for viscosities of $12 \mathrm{cps}$ with rotational speeds ranging from 400 to 800 rpm to achieve complete suspension. Thus, mixing speed of the WESTLAKE ZHX-13 drilling machine was used $(515,915$, and $1430 \mathrm{rpm}$ ) to rotate a general dual blade paddle of $5 \mathrm{~cm}$ in length for one minute. The suspension was then degassed in a vacuum chamber with a pressure of negative $90 \mathrm{kPa}$. The time of degassing was more than 7.5 minutes (Kraume, 1992). Mixture was applied with hardener and poured into 31 $\mathrm{cm} \times 31 \mathrm{~cm} \times 0.3 \mathrm{~cm}$ mold which includes fiber glass. The mixture was kept to be hardened and then cured in $60^{\circ} \mathrm{C}$ where it would be continued until total curing process. Several microscopy samples were taken and processed referring to Yakaboylu's method. The composite panel was analyzed by its microstructure using a digital microscope for its homogeneity. Based on its free-path spacing, a grid was developed upon its microstructure of binary image, processed using an ImageJ software and determined of its scaling in micrometers where it would be further processed. Each line is determined:

$\overline{X_{h 1}}=\frac{1}{n} \sum_{i=1}^{n} X i ; \overline{X_{v 1}}=\frac{1}{n} \sum_{i=1}^{n} X i ;$

where $h$ and $v$ are the abbreviations of horizontal and vertical lines, respectively. $n$ is the number of free path spacing on a specific line drawn. Figure $\mathbf{1}$ displays a horizontal and vertical $X_{1}$. These $X$ values as the equation (1) suggested are summed from this spacing to obtain $\overline{X_{h 1}}$ from the horizontal $X_{1}$ and likewise for $\overline{X_{v 1}}$ the vertical $X_{1}$. 


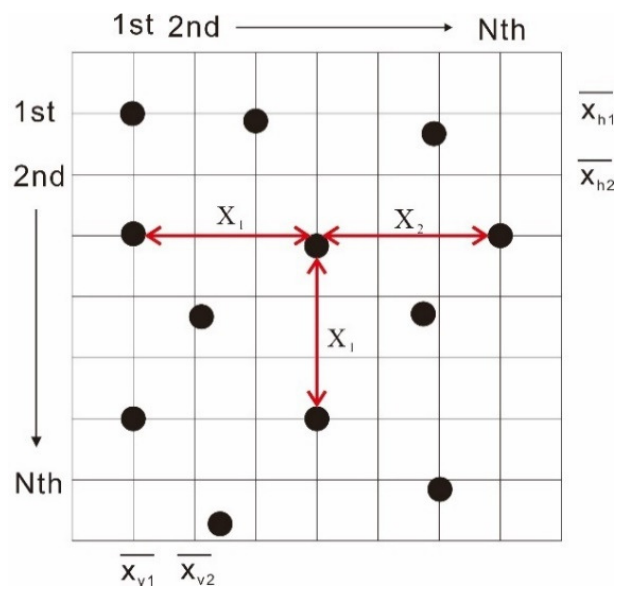

Figure 1. Schematic diagram of free-path spacing image analysis. Black dots represent the particles in the sample.

The arithmetic mean $(\bar{X})$ and standard deviation $(s)$ is then continued to be calculated:

$\bar{X}=\frac{\left(\overline{X_{h 1}}+\overline{X_{h 2}}+\ldots+\overline{X_{h N}}\right)+\left(\overline{X_{h 1}}+\overline{X_{h 2}}+\ldots+\overline{X_{h N}}\right)}{2 N}$

where values of $X_{h}$ and $X_{v}$ are derived from equation (1). Homogeneity is considered when the arithmetic mean values of the free spacing is similar in each line analyzed. The values on each line has varieties and the standard deviation is analyzed through $\bar{X}$ of equation (2), thus the $C v$ or the coefficient of variation is determined to access variety of free path spacing for $2 \mathrm{~N}$ lines. $\mathrm{CV}$ could be written as:

$$
C v=\left(\frac{s}{X}\right)
$$

The value of $C v=0$ is determined to be perfectly homogeneous composite material, and their arithmetic mean values on each line are the same. The increases in agglomeration would increase the value of inhomogeneity. Indee, the Cv value would also increase.

\section{RESULTS AND DISCUSSION}

The finished square panel resulted in a dark brown board. Panel observation is conducted at three main points on the material. From cartesian coordinate point of view in centimeters where the bottom left corner is the $(0,0)$ point, we observed point $1(7 \mathrm{~cm}, 5 \mathrm{~cm})$, point $2(27 \mathrm{~cm}, 15 \mathrm{~cm})$, and point $3(15 \mathrm{~cm}, 25 \mathrm{~cm})$ as indicated in Figure 2. The experimental results show $C_{V}$ of the three respective points on the plane.

The binary images developed from the digital microscope has shown excellent particle dispersion, representing the microstructure of the composite. Coffee particles tended to agglomerate in the certain parts. These agglomerations develop on certain areas and leave voidages in the matrix, informing no or less number of particles in some areas.

In the limited time of mixing, low-speed homogeneity of the particles would not have the most stable results as different points of the structure have different homogeneities indexes (see Table 1). The samples for lower mixing speed (i.e., 515 rpm) had more varieties of dispersion. Increases in the mixing speed can allow increases in the the homogeneity index. The highest mixing speed (i.e., $1420 \mathrm{rpm}$ ) has less variation between the samples. Homogeneity on the highest speed were the most stable in terms of results between the points in homogeneity index among the other mixing speeds. 
To confirm the analysis, all data were categorized based on the homogeneity index (Yakaboylu and Sabolsky, 2017). The degree of dispersion can be classified into high level of homogeneity (between 0 and $0.25)$, moderate level of homogeneity (between 0.25 and 0.40 ), low level of homogeneity (between 0.40 and 0.60 ) and very low level of homogeneity (more than $0.60)$. In the study, all the average results were located in the "high" region of dispersion. Therefore, it can be concluded that the samples were in the high degree of distribution. However, there were large variations within the microstructure with mixing speeds of 415 and 915 rpm, indicating a low distribution of particle dispersion on specific points of the microstructure.

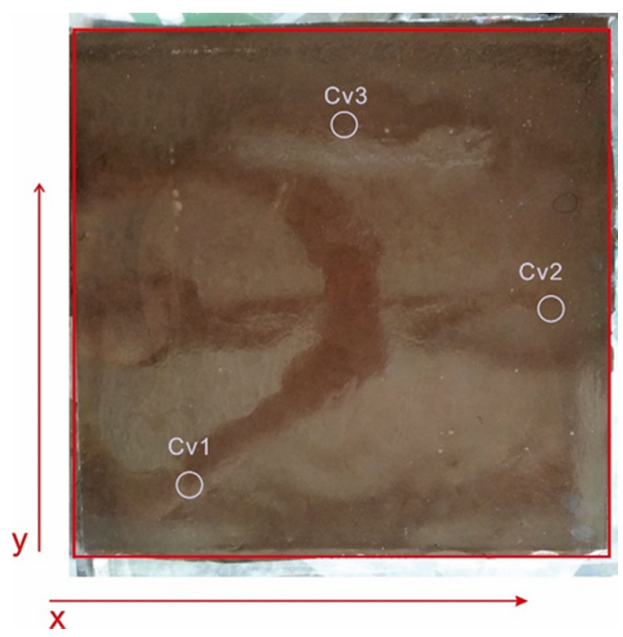

Figure 2. SCG composite panel using $515 \mathrm{rpm}$ mixing speed and points of interest in microstructure image processing.

As the densities of the solid and liquid materials were determined to be lower for the solids, the solids were considered to be neutrally buoyant. This would result in the need of a high suspension velocity to disperse the particles radially. Dispersing these particles rapidly would be essentially dispel the local accumulations (Roni et al., 2019). This principle signifies that the speed of mixing would inherently affect the dispersion of the solid (Bujalski et al., 1999; Rao and Joshi, 1988). We could achieve faster homogeneity with higher mixing speeds. A lower mixing speed would require longer mixing time. Hence, the more variety in homogeneity factors would result the lower speed mixed composites.
Figure 3 shows significant differences in the microstructure of the three different speeds. The result of lower speed is dominated by smaller clumps of particles. Agglomeration and combined particles (large clusters) were found, informing incomplete dispersion. The higher aggregation and combined particles increases, and they appear in the microstructure. The lower mixing speed has a different formation of solid-liquid interface compared to the higher mixing speed. In fact, the interface will create different types of composite (Kraume, 1992; Fu et al., 2008; Van de Velde and Kiekens, 1999) since it depends on various factors, such as compaction of molecular shape, surface free energy, chemical potential, and molecular 
composition among others. However, these factors are not comparable to a pile-up particles in the suspension of the mixture (Uhlmann et al., 1964). As the higher speeds develop more clumps between the particles, it does not necessarily suggest a decrease in surface area contact between the matrix and the particle. Forces such a capillary forces and other various forces such as adhesion will take part. But, ultimately for a solid-liquid mixture, the contact angle, dynamic conditions, and surface roughness would become the main parameters in the surface tension (Roni et al., 2019).
Higher mixing speed allows more energy in a unit area of free surface. The surface tension or surface energy will bring positive impact on cohesion (Roni et al., 2019). And, this cohesion affects surface areas and gives benefit on maintaining a homogenous distribution of particle mixture from various points in the final structure. High levels of $C V$ on many points of a microstructure would give a good homogeneity of the overall structure.

Table 1. Homogeneity of three different areas of SCG composite.

\begin{tabular}{cllll}
\hline Mixing speeds & Cv1 & Cv2 & Cv3 & AVG \\
\hline 515 RPM & 0.145 & 0.259 & 0.189 & 0.198 \\
915 RPM & 0.199 & 0.283 & 0.222 & 0.235 \\
1430 RPM & 0.198 & 0.195 & 0.183 & 0.192 \\
\hline
\end{tabular}

(a)

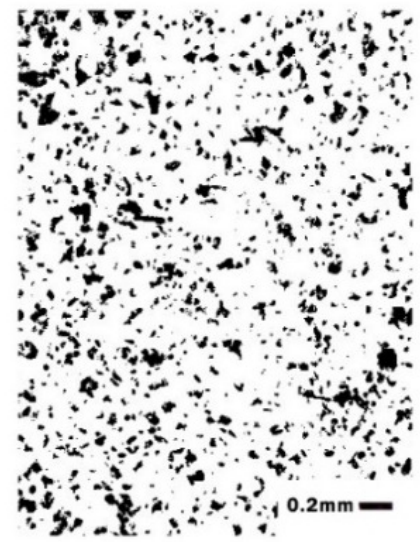

(b)

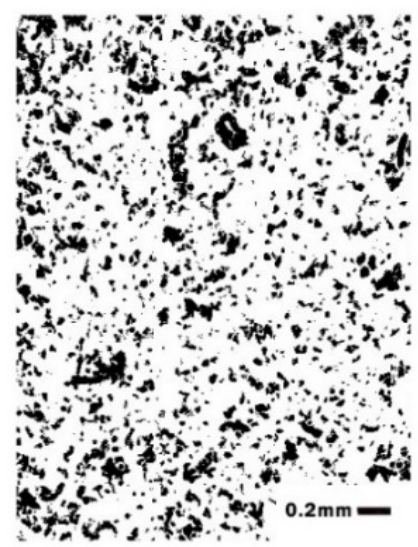

(c)

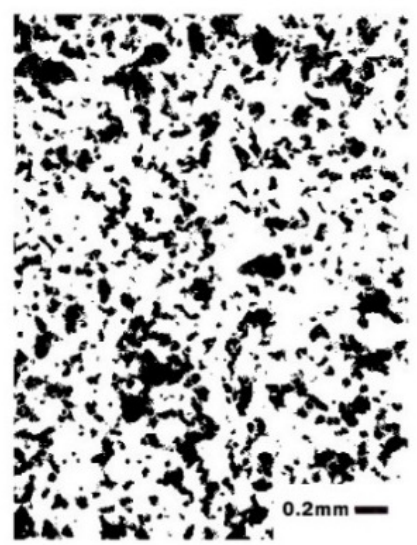

Figure 3. Typical binary microstructure microscopy of SCG composites with mixing speeds of (a) 515, (b) 915 , and (c) $1430 \mathrm{rpm}$.

\section{CONCLUSION}

Optical microscope completed with image processing software is effective to determine the SCG dispersion. To confirm the analysis, this study varied the samples, specifically the mixing speed and the particle homogeneity. The results showed that the high-speed mixing can allow the highest homogeneity results. On the contrary, low speeds have given almost the same homogeneity levels, but the dispersion type of sample depends on the position in the sample. The high-speed mixing is also the best since it can permit the dispersion for shorter time and develop better wetting condition between matrix and filler. 


\section{ACKNOWLEDGEMENTS}

This work was supported by Material Research Group, Department of Mechanical Engineering, University of Jember, Jember, Indonesia.

\section{AUTHORS' NOTE}

The author(s) declare(s) that there is no conflict of interest regarding the publication of this article. Authors confirmed that the data and the paper are free of plagiarism.

\section{REFERENCES}

Barabash, V. M., Abiev, R. S., and Kulov, N. N. (2018). Theory and practice of mixing: A review. Theoretical Foundations of Chemical Engineering, 52(4), 473-487.

Bale, J. S., Pell, Y. M., Jafri, M., and Selan, R. Experimental Investigation on Mechanical Joint of Lontar (Borassus Flabellifer) Fiber Reinforced Polyester Composites under Static Flexural Test. Indonesian Journal of Science and Technology, 4(1), 17-27.

Bujalski, W., Takenaka, K., Paoleni, S., Jahoda, M., Paglianti, A., Takahashi, K., and Etchells, A. W. (1999). Suspension and liquid homogenization in high solids concentration stirred chemical reactors. Chemical Engineering Research and Design, 77(3), 241-247.

Chavan, A. A., Pinto, J., Liakos, I., Bayer, I. S., Lauciello, S., Athanassiou, A., and Fragouli, D. (2016). Spent coffee bioelastomeric composite foams for the removal of $\mathrm{Pb}^{2+}$ and $\mathrm{Hg}^{2+}$ from water. ACS Sustainable Chemistry and Engineering, 4(10), 5495-5502.

de Melo, M. M., Barbosa, H. M., Passos, C. P., and Silva, C. M. (2014). Supercritical fluid extraction of spent coffee grounds: measurement of extraction curves, oil characterization and economic analysis. The Journal of Supercritical Fluids, 86, 150-159.

Elkington, M., Bloom, D., Ward, C., Chatzimichali, A., and Potter, K. (2015). Hand layup: understanding the manual process. Advanced Manufacturing: Polymer and Composites Science, 1(3), 138-151.

Fu, S. Y., Feng, X. Q., Lauke, B., and Mai, Y. W. (2008). Effects of particle size, particle/matrix interface adhesion and particle loading on mechanical properties of particulatepolymer composites. Composites Part B: Engineering, 39(6), 933-961.

Kraume, M. (1992). Mixing times in stirred suspensions. Chemical Engineering and Technology: Industrial Chemistry-Plant Equipment-Process Engineering-Biotechnology, 15(5), 313-318.

Luo, Z. P., and Koo, J. H. (2007). Quantifying the dispersion of mixture microstructures. Journal of Microscopy, 225(2), 118-125.

Mavhungu, S. T., Akinlabi, E. T., Onitiri, M. A., and Varachia, F. M. (2017). Aluminum matrix composites for industrial use: advances and trends. Procedia Manufacturing, 7, 178182. 
195 | Indonesian Journal of Science \& Technology, Volume 4 Issue 2, September 2019 page 188-195

Mohanty, A. K., Vivekanandhan, S., Pin, J. M., and Misra, M. (2018). Composites from renewable and sustainable resources: Challenges and innovations. Science, 362(6414), 536-542.

Oh, S. T., Sekino, T., and Niihara, K. (1998). Effect of particle size distribution and mixing homogeneity on microstructure and strength of alumina/copper composites. Nanostructured Materials, 10(2), 327-332.

Paciornik, S. A., and d'Almeida, J. R. M. (2009). Measurement of void content and distribution in composite materials through digital microscopy. Journal of Composite Materials, 43(2), 101-112.

Prabu, S. B., Karunamoorthy, L., Kathiresan, S., and Mohan, B. (2006). Influence of stirring speed and stirring time on distribution of particles in cast metal matrix composite. Journal of Materials Processing Technology, 171(2), 268-273.

Rao, K. R., and Joshi, J. B. (1988). Liquid-phase mixing and power consumption in mechanically agitated solid-liquid contactors. The Chemical Engineering Journal, 39(2), 111-124.

Roni, P., Max, M., François-Gaël, M., Andreas, S., Jiande, Z., and Markus, H. (2019). Quantifying physical disintegration of faeces in sewers: Stochastic model and flow reactor experiments. Water Research, 152, 159-170.

Uhlmann, D. R., Chalmers, B., and Jackson, K. A. (1964). Interaction between particles and a solid-liquid interface. Journal of Applied Physics, 35(10), 2986-2993.

Van de Velde, K., and Kiekens, P. (1999). Wettability of natural fibres used as reinforcement for composites. Die Angewandte Makromolekulare Chemie, 272(1), 87-93.

Woo, E. J., Oh, Y. J., Yoo, J. Y., and Park, C. J. (2017). On the Control Process of Odor Material by Using Coffee Wastes. International Journal of Environmental Science and Development, 8(4), 281.

Wu, C. S. (2015). Renewable resource-based green composites of surface-treated spent coffee grounds and polylactide: Characterisation and biodegradability. Polymer Degradation and Stability, 121, 51-59.

Yakaboylu, G. A., and Sabolsky, E. M. (2017). Determination of a homogeneity factor for composite materials by a microstructural image analysis method. Journal of Microscopy, 266(3), 263-272.

Zarrinbakhsh, N., Wang, T., Rodriguez-Uribe, A., Misra, M., and Mohanty, A. K. (2016). Characterization of wastes and coproducts from the coffee industry for composite material production. BioResources, 11(3), 7637-7653. 